\title{
A clade of telosma mosaic virus from Thailand is undergoing geographical expansion and genetic differentiation in passionfruit of Vietnam and China
}

\author{
Chaowei Yu ${ }^{1}$, Qin Lian ${ }^{1}$, Huihuang Lin ${ }^{1}$, Lei Chen ${ }^{1}$, Yizhong Lu', Yingying Zhai ${ }^{1}$, Xing Han ${ }^{1}$, Zhenguo Du ${ }^{1,2}$,
} Fangluan $\mathrm{Gao}^{1,2^{*}}$ (I) and Zujian $\mathrm{Wu}^{1,2^{*}}$

\begin{abstract}
Passionfruit (Passiflora edulis) is widely cultivated in tropical and subtropical regions around the world. Several viruses of the genus Potyvirus pose serious threat to passion fruit production. The origin, dispersal and evolution of these potyviruses, however, are poorly understood. Here, we investigated the genetic structure of telosma mosaic virus (TelMV), a potyvirus that infects passionfruit in East and Southeast Asia, after a survey of its incidence in passionfruit plants of China. The phylogeny inferred from 140 nucleotide sequences of the coat protein (CP) gene of TelMV, including 96 determined in this study, separated this virus into 4 clades. TelMV isolates from passionfruit were placed into Clade 1-3, while those from other plant species into Clade 4. Interestingly, TelMV isolates of passionfruit from Thailand were found in all the three clades of Clade 1-3, but those from China and Vietnam were found exclusively in Clade 1. Nevertheless, TeIMV isolates within Clade 1 tended to cluster according to their geographical origin. Geographical populations from Thailand, Taiwan and Hainan islands of China showed significant genetic differences with one another and with those from Guangxi, Fujian, Guangdong, Yunnan and Jiangsu provinces of China. Altogether, these data suggest that several distinct TelMV clades had arisen from the passionfruit of Thailand, but only one of which was dispersed. In expanding its distribution, this clade of TelMV has undergone geography-associated evolution. Further studies on this hypothesis may shed new insights into mechanisms underlying the emergence of potyviral diseases in passionfruit plants.
\end{abstract}

Keywords: Passionfruit, Telosma mosaic virus, Genetic diversity, Phylogeography, Passionfruit woodiness disease

\section{Background}

Native to South America, passionfruit (Passiflora edulis) has been widely dispersed in tropical and subtropical regions around the world (Manicom et al. 2003). In some underdeveloped countries, passionfruit has been adopted as an important economic plant to increase the income

*Correspondence: raindy@fafu.edu.cn; wuzujian@fafu.edu.cn

${ }^{1}$ Institute of Plant Virology, Fujian Agriculture and Forestry University, Fuzhou 350002, China

Full list of author information is available at the end of the article of poor peasants (Ochwo-Ssemakula et al. 2011). There are two main types of passionfruit: $f$. edulis with purple fruits and $f$. flavicarpa Degener with larger yellow fruits. Many countries grow both varieties (Lim 2012).

A viral disease called passionfruit woodiness disease (PWD) is prevalent in all major passionfruit growing areas of the world (Cerqueira-Silva et al. 2014). Passionfruit plants affected by PWD exhibit a wide range of symptoms from leaf mosaic to woodiness and deformation of the fruits. Collectively, these abnormities shorten the lifespan of passionfruit and cause significant yield original author(s) and the source, provide a link to the Creative Commons licence, and indicate if changes were made. The images or other third party material in this article are included in the article's Creative Commons licence, unless indicated otherwise in a credit line to the material. If material is not included in the article's Creative Commons licence and your intended use is not permitted by statutory regulation or exceeds the permitted use, you will need to obtain permission directly from the copyright holder. To view a copy of this licence, visit http://creativecommons.org/licenses/by/4.0/. 
losses (Ochwo-Ssemakula et al. 2011). The causal agent of PWD was identified to be passionfruit woodiness virus (PWV) in 1973 in Australia (Taylor and Greber 1973). For decades, PWV had been considered to be responsible for the PWD in other regions of the world as well. Later studies, however, found that the causal agent of PWD in Brazil and South Africa is cowpea aphid-borne mosaic virus (CABMV), while that in Japan is East Asian Passiflora virus (EAPV) (Iwai et al. 2006). More recently, many other viruses were reported to cause PWD, some of which, like Ugandan passiflora virus, have been shown to be a limiting factor for passionfruit production locally (Ochwo-Ssemakula et al. 2011; Mbeyagala et al. 2019). Despite their diversity in species and differences in geographical distribution, all PWD-causing viruses are positive-sense RNA viruses belonging to the genus Potyvirus under the family Potyviridae (Lefkowitz et al. 2018). Clearly, an understanding of the process by which these potyviruses emerge on passionfruit is helpful in managing PWD. However, studies that can meet this demand are scarce in the literature. The only information of relevance is that many potyviruses had been identified from other plant species before they were known to infect passionfruit. This suggests that at least some potyviruses are jumped to passionfruit from other plants.

Passionfruit acreage soared in the past decade in Asia. In China's mainland alone, the planting areas of passionfruit have reached approximately 30,000 ha. Not unexpectedly, potyviruses other than EAPV have also been found to cause PWD in Asia (Chang 1992). One of these potyviruses is telosma mosaic virus (TelMV). The occurrence of TelMV in passionfruit was first reported from Thailand in 2014 (Chiemsombat et al. 2014). Shortly thereafter, TelMV was detected in passionfruit in several different provinces of China's mainland, as well as in Taiwan region (Xie et al. 2017; Chen et al. 2018). More recently, TelMV was detected from passionfruit in Vietnam (Ha et al. 2008; Do et al. 2021). The first known plant host of TelMV is not passionfruit. Instead, it was first detected from telosma in Vietnam (Ha 2007). Besides telosma, TelMV was found to infect patchouli in Indonesia and Emperor's Candlesticks (Senna alata) in Yunnan Province of China (Yao et al. 2019). These observations suggest that TelMV has a wide host range and is widely distributed in East and Southeast Asia. Considering the short history of passionfruit cultivation in Asia, it is not unconservative to assume that the TelMV infecting passionfruit comes from a recent host jump event involving one or several non-passionfruit plant species.

Given the background described above, this study aimed to: (i) get an overview on the incidence of TelMV in passionfruit plants in China; (ii) characterize the genetic structure of TelMV to facilitate our understanding of its origin and dispersal; (iii) gain a primary knowledge on the relationship between TelMV infecting passionfruit and other plant species. For these purposes, we randomly collected 508 passionfruit plant samples from 7 provinces of China and detected the presence of TelMV in these samples. Furthermore, we determined the nucleotide sequences of the coat protein (CP) cistrons of TelMV from 96 representative samples and analyzed them together with relevant sequences from public databases. The results provide some new insights into the epidemiology of TelMV.

\section{Results \\ The pervasiveness of TelMV in China}

In Thailand, TelMV seems to be the dominating potyvirus affecting passionfruit production, with a detection rate of about $55 \%$ in field samples (Chiemsombat et al. 2014). In Vietnam, however, TelMV has a very low incidence (Ha et al. 2008). This uneven distribution of TelMV in Southeast Asia promoted us to investigate its incidence in China. RT-PCR analysis was used to detect TelMV infection in passionfruit plants. TelMV was detected from 373 out of the 508 samples collected from 7 provinces of China's mainland (Fig. 1a). For the purple and yellow passionfruit, TelMV was detected from 178 out of 248 and 195 out of 260 samples, respectively (Fig. 1b). The detection rate of TelMV in different provinces varies substantially. However, all the 4 major passionfruit growing provinces, Guangxi, Fujian, Hainan and Guangdong, showed a high detection rate. Prominently, Fujian and Guangxi, the two largest passionfruit producers, both have a detection rate of above $80 \%$ (Fig. 1c). Altogether, the data showed that TelMV is pervasive in passionfruit plants in China, especially in these major passionfruitproducing regions. It is interesting to note that 145 of the 508 samples collected in this study were symptomless. However, TelMV was detected from 29 of them.

\section{The phylogeographic structure of TelMV}

The phylogeny reconstructed based on the CP gene sequences separated TelMV into 4 well-resolved clades named Clade 1-4 in this study (Fig. 2). TelMV isolates from passionfruit were placed into Clade 1-3, while those from telosma or Emperor's Candlesticks were placed into Clade 4. However, Clade 3 shares a more recent common ancestor with Clade 4 than with Clade 1 or 2 . An interesting observation was made when the geographical origins of the TelMV isolates in Clade 1-3 were examined: TelMV isolates from Thailand were found in all the three clades, but those from China and Vietnam were found exclusively in Clade 1 (Fig. 2). 
Province

- Fujian(FJ)

- Guangdong(GD)

- Guangxi(GX)

- $\operatorname{Hainan}(\mathrm{HN})$

- Jiangsu(JS)

- Sichuan(SC)

- Yunnan(YN)

b

negative positive

C

egative positive

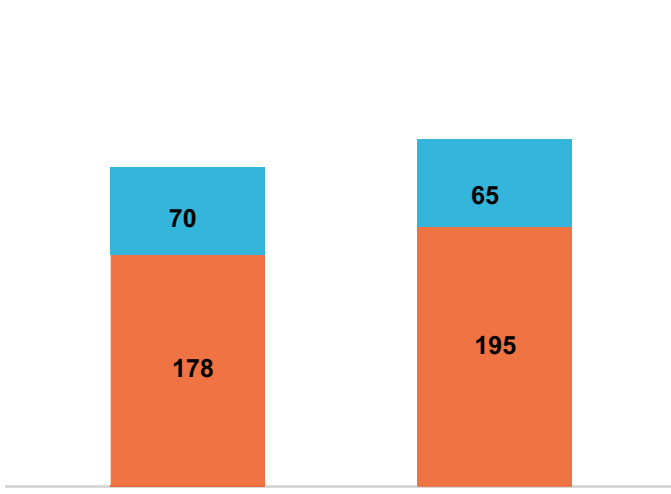

Purple passionfruit Yellow passionfruit
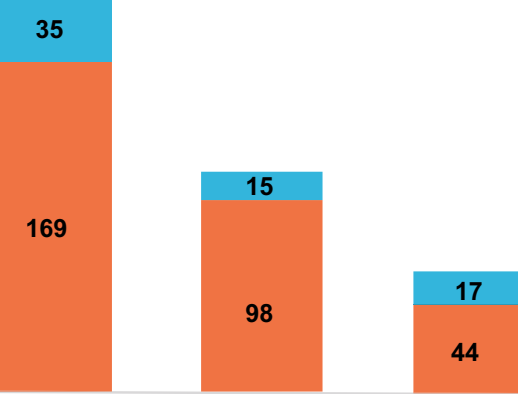

\section{0 \\ 35}

Fig. 1 The incidence of TelMV in China's mainland. a Map showing the location of TelMV isolates collected in this study. b TelMV detection rates from purple and yellow passionfruit plants. c TelMV detection rates from passionfruit plant samples collected from Fujian, Guangxi, Guangdong and Hainan provinces 


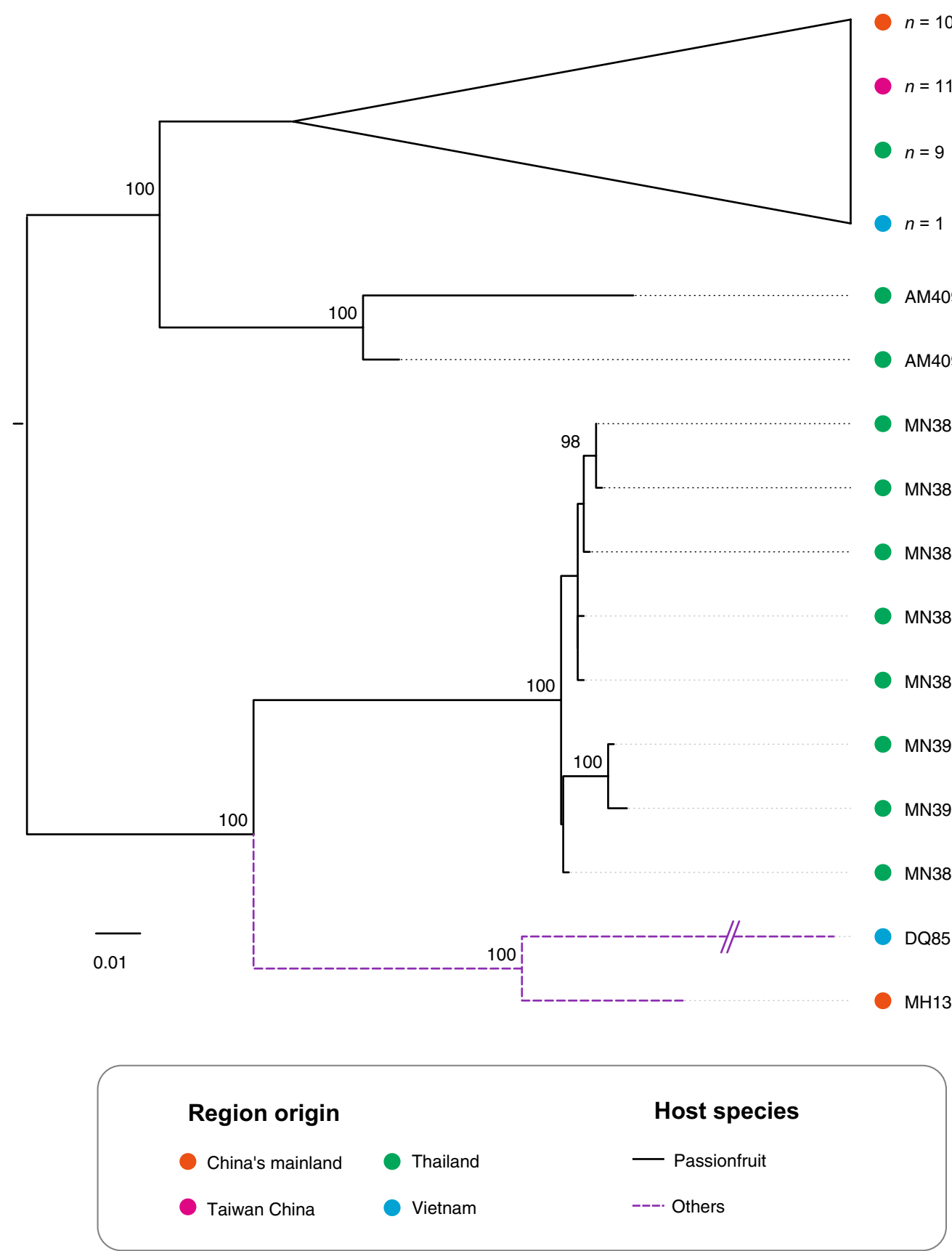

Fig. 2 Maximum-likelihood phylogenetic tree based on the nucleotide sequences of the coat protein gene of TelMV. Ultrafast bootstrap support $>95 \%$ values are given at each node. The bar represents the number of substitutions per site

\section{Geographical differentiation of Clade 1 TelMV}

In the phylogenetic tree, TelMV isolates in Clade 1 formed a comb-like structure. Nevertheless, many isolates sharing the same geographical origin tend to form sub-clades with well-supported bootstrap values (Additional file 1: Figure S1). This suggests that TelMV isolates from Clade 1 are clustered according to their geographical origin. Indeed, phylogeny-trait association analysis supports this idea (AI and PS, $P<0.001$ ) (Table 1). With TelMV isolates from Anhui and Yunnan provinces as exceptions $(\mathrm{MC}=1.07$ and 1.04 , respectively, $P>0.05$ ), significant signal of geographic clustering was observed when TelMV isolates were grouped by their geographical origins $(\mathrm{MC}: P<0.05)$ (Table 1$)$. 
Table 1 Pairwise $F_{\text {ST }}$ between TelMV subpopulations within Clade 1

\begin{tabular}{lllllllll}
\hline & AH & FJ & GD & GX & HN & JS & YN & TL \\
\hline AH & - & & & & & \\
FJ & $0.21^{* *}$ & - & & & & \\
GD & $-0.04^{\text {ns }}$ & $0.17^{* *}$ & - & & & \\
GX & $0.13^{*}$ & $0.02^{\text {ns }}$ & $0.08^{*}$ & - & & & \\
HN & $0.64^{* * *}$ & $0.32^{* * *}$ & $0.59^{* * *}$ & $0.38^{* * *}$ & - & & \\
JS & $-0.04^{\text {ns }}$ & $0.17^{* *}$ & $-0.04^{\text {ns }}$ & $0.09^{*}$ & $0.58^{* * *}$ & - & & \\
YN & $0.04^{\text {ns }}$ & $0.13^{\text {ns }}$ & $0.05^{\text {ns }}$ & $0.06^{\text {ns }}$ & $0.42^{* * *}$ & $0.07^{\text {ns }}$ & - & - \\
TL & $0.39^{* * *}$ & $0.26^{* * *}$ & $0.38^{* * *}$ & $0.27^{* * *}$ & $0.28^{* * *}$ & $0.41^{* * *}$ & $0.25^{* * *}$ & - \\
TW & $0.82^{* * *}$ & $0.46^{* * *}$ & $0.74^{* * *}$ & $0.52^{* * *}$ & $0.61^{* * *}$ & $0.72^{* * *}$ & $0.57^{* * *}$ & $0.38^{* * *}$ \\
\hline
\end{tabular}

Negative $F_{\mathrm{ST}}$ value indicates an excess of heterozygotes; ns, not significant

Significance thresholds: ${ }^{*} 0.01<P<0.05 ;{ }^{* *} 0.001<P<0.01 ;{ }^{* * *} P<0.001$; Viral isolates from Vietnam were excluded from the analysis because of insufficient size ( $n<3$ )

Given this observation, the statistic $F_{\mathrm{ST}}$ was used to assess the differentiation between geographical populations of Clade 1 TelMV. As presented in Table 2, TelMV populations from Thailand, Taiwan and Hainan of China are significantly differentiated from all the other populations. In most pairwise comparisons involving these 3 populations, $F_{\mathrm{ST}}$ values are greater than 0.33 , indicating infrequent gene flow between each of these 3 populations and any other populations. However, the differentiation among TelMV populations of Anhui, Fujian, Guangdong, Guangxi, Jiangsu and Yunnan provinces is significant only for a few pairwise comparisons. In all pairwise comparisons, $F_{\mathrm{ST}}$ values are much lower than 0.33 , indicating frequent gene flow among the 6 populations.

Altogether, these results indicate genetic differentiation between geographical groups of Clade 1 TelMV isolates. However, the differentiation level between geographical groups within China's mainland is low, possibly because of frequent gene flow.

\section{Natural selection acting on Clade 1 TelMV}

Primarily, geographical differentiation is a result of adaptation. In principle, adaptative evolution leads to genetic diversification. However, the nucleotide diversity $(\pi)$ of TelMV isolates in Clade 1 is modest, at a value of 0.031 . This suggests that selection may have a role in shaping the genetic structure of Clade 1 TelMV. The selection pressures acting on Clade 1 TelMV were investigated subsequently. Using CodeML, we found that most $C P$ codons of Clade 1 TelMV were under negative selection, with a $d \mathrm{~N} / d \mathrm{~S}$ value much lower than 1 (Fig. 3). However, significant evidence for positive selection was detected for codons specifying amino acid positions 20,23, 28, 34 and 46 of CP (Table 3). As a comparison, no evidence for positive selection was detected from Clade 3 TelMV (Additional file 2: Table S1).

Table 2 Putative codons in the coding sequence of the TelMV CP gene identified under positive selection within Clade 1

\begin{tabular}{|c|c|c|c|c|c|c|}
\hline Model & np & $\operatorname{Ln} \mathrm{L}$ & Estimates of parameters & Model compared & LRT & Positive sites \\
\hline MO & 256 & -4380.480 & $\omega_{0}=0.187$ & M0 vs. M3 & $<0.001$ & Not allowed \\
\hline M3 & 260 & -4212.443 & $\begin{array}{l}p_{0}=0.871, p_{1}=0.106, p_{2}=0.022 \\
\omega_{0}=0.040, \omega_{1}=0.930, \omega_{2}=4.067\end{array}$ & & & $\mathrm{n} / \mathrm{a}$ \\
\hline M1a & 257 & -4234.674 & $\begin{array}{l}p_{0}=0.877, p_{1}=0.123 \\
\omega_{0}=0.038, \omega_{1}=1.000\end{array}$ & M1a vs. M2a & $<0.001$ & $\mathrm{n} / \mathrm{a}$ \\
\hline M2a & 259 & -4211.067 & $\begin{array}{l}p_{0}=0.875, p_{1}=0.104, p_{2}=0.021 \\
\omega_{0}=0.041, \omega_{1}=1.000, \omega_{2}=4.328\end{array}$ & & & Not allowed \\
\hline M7 & 257 & -4258.473 & $p=0.054, q=0.074$ & M7 vs. M8 & $<0.001$ & Not allowed \\
\hline M8 & 259 & -4214.917 & $\begin{array}{l}p_{0}=0.954, p=0.088, q=0.565 \\
p_{1}=0.046, \omega=2.842\end{array}$ & & & $20^{* *}, 23^{* *}, 28^{* *}, 34^{*}, 46^{* *}$ \\
\hline M8a & 258 & -4233.006 & $\begin{array}{l}p_{0}=0.887, p=0.609, q=12.944 \\
p_{1}=0.113, \omega=1.000\end{array}$ & M8a vs. M8 & $<0.001$ & Not allowed \\
\hline
\end{tabular}




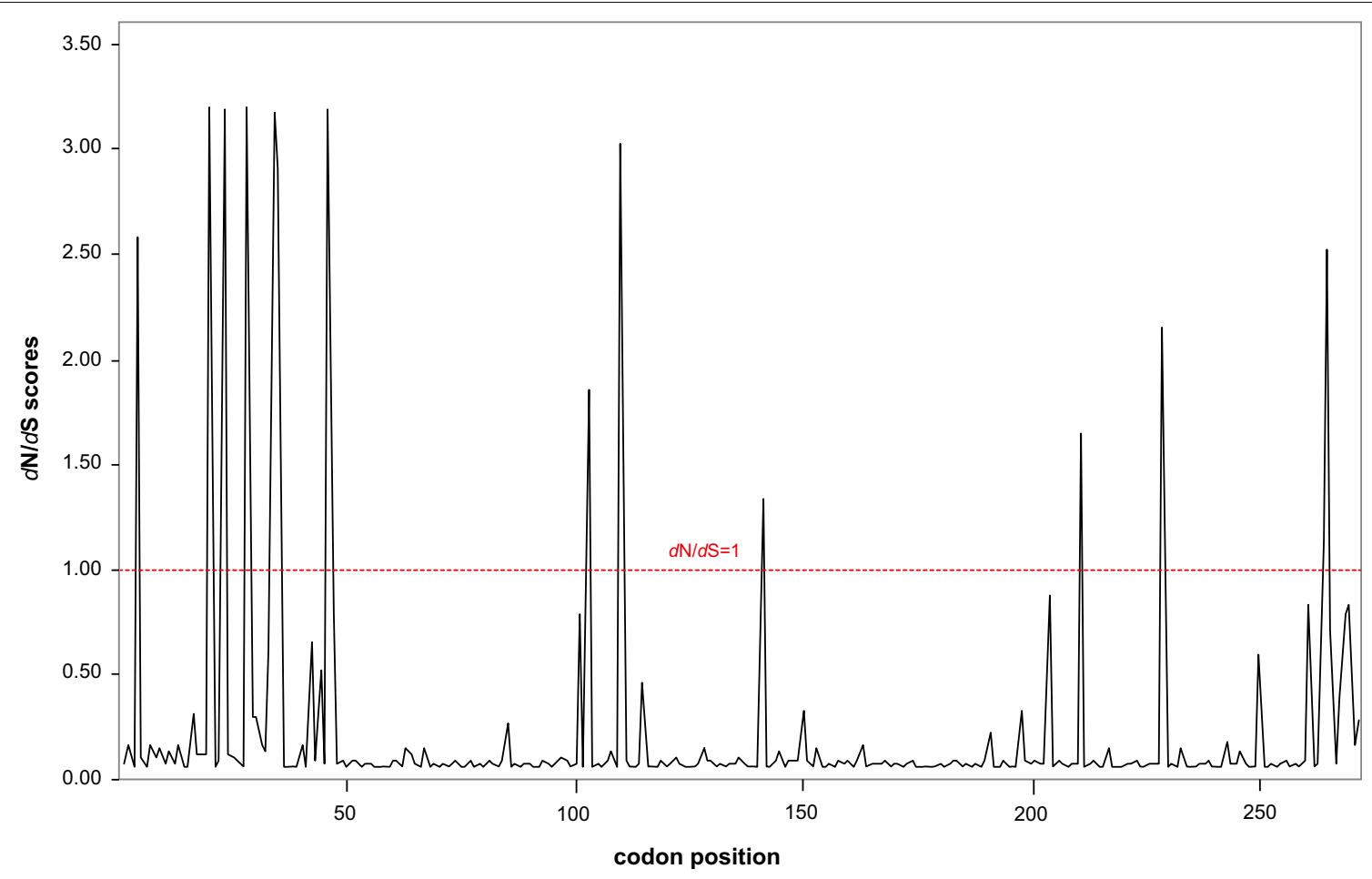

Fig. 3 Sliding windows analysis for the $d N / d S$ ratios produced by the site models of CodeML implemented in EasyCodeML. A red dotted line represents where $d N / d S=1$, consistent with the neutral expectation

Table 3 Phylogeny-trait association test for phylogeographic structure of TelMV

\begin{tabular}{llccr}
\hline Analyses & Statistic & Observed mean (95\% HPD Cls) & Null mean (95\% HPD Cls) & $p$ value \\
\hline & Al & $5.95(5.02,6.86)$ & $14.10(13.17,14.90)$ & $<0.001^{* * *}$ \\
& PS & $51.60(48.00,54.00)$ & $93.71(90.06,97.28)$ & $<0.001^{* * *}$ \\
AH & MC & $1.07(1.00,2.00)$ & $1.11(1.00,1.60)$ & $1.000^{\text {ns }}$ \\
FJ & MC & $7.71(4.00,12.00)$ & $2.13(1.55,3.06)$ & $0.010^{* *}$ \\
GD & MC & $1.88(1.00,2.00)$ & $1.26(1.00,1.99)$ & $0.050^{*}$ \\
GX & MC & $3.28(3.00,4.00)$ & $1.73(1.19,2.59)$ & $0.020^{* *}$ \\
HN & MC & $11.85(11.00,13.00)$ & $1.52(1.03,2.03)$ & $0.010^{* *}$ \\
JS & MC & $1.89(1.00,3.00)$ & $1.45(1.02,1.99)$ & $0.040^{*}$ \\
YN & MC & $1.04(1.00,1.00)$ & $1.09(1.00,1.60)$ & $1.000^{\text {ns }}$ \\
TW & MC & $6.67(5.00,11.00)$ & $1.22(1.00,1.82)$ & $0.010^{* *}$ \\
TL & MC & $3.98(3.00,4.00)$ & $1.17(1.00,1.86)$ & $0.010^{* *}$ \\
\hline
\end{tabular}

Al, Association index; PS, Parsimony score; MC, Maximum monophyletic clade; HPD Cls: Highest posterior density confidence intervals Significance thresholds: ${ }^{*} 0.01<p<0.05 ;{ }^{* *} 0.001<p<0.01 ;{ }^{* * *} p<0.001$; ns, not significant

\section{Discussion}

A survey on the occurrence of TelMV in passionfruit plants in China was conducted in this study. Furthermore, we investigated the genetic structure of TelMV to understand its origin, dispersal and evolution during the spread of infection in passionfruit plants in East and Southeast Asia.
Taiwan has a much longer history of passionfruit cultivation than most other regions of East and Southeast Asia (Chong et al. 2018). In the past decade, Taiwan has served as a center for the dispersal of passionfruit propagation materials. Therefore, it is anticipated that EAPV, or some other virus species that had been prevalent in Taiwan, will be the dominating potyvirus in the passionfruit 
of China's mainland, as it has been demonstrated in Vietnam (Do et al. 2021). The results of this study do not provide direct evidence to deny this assumption. However, the data of our survey showed that the incidence of TelMV is $>80 \%$ in major passionfruit growing regions of China's mainland. It seems unlikely for any other potyviruses to have a value greater than this. Therefore, besides providing an overview for the distribution of TelMV in China, the results of this study suggest that TelMV has become an important, if not the most important, potyvirus affecting passionfruit in East Asia. Noteworthily, about $20 \%$ of the symptomless passionfruit samples collected in this study were positive for TelMV. Although the mechanisms underlying this observation are unclear at present, symptomless infection may have facilitated the dispersal of TelMV through propagation materials.

Conventional measures for managing potyviruses in passionfruit are expensive. Many researchers therefore are making efforts to develop strategies involving engineered resistance, cross protection and resistant germplasms (Peasley 1981; Alfenas et al. 2005; Trevisan 2005). Successful deployment of these strategies requires knowledge about the genetic structure of the potyvirus being targeted. For controlling potyviruses distributed across countries, an understanding of their origin, dispersal and evolution is helpful and necessary (Rubio et al. 2020). On this account, we investigated the genetic structure of TelMV. Two observations are surprising, if not totally unexpected. Firstly, all TelMV isolates infecting passionfruit are phylogenetically separable from those infecting telosma or Emperor's Candlesticks. Since the full-length $\mathrm{CP}$ gene sequences of the TelMV isolates infecting patchouli in Indonesia are unavailable, a phylogenetic tree was constructed with truncated TelMV CP sequences. A similar topology was obtained: all TelMV isolates from non-passionfruit plants were placed into a clade, which is distinct from those formed by the TelMV isolates from passionfruit (data not shown). Secondly, all TelMV isolates of passionfruit from China and Vietnam were placed into one of the three clades formed by TelMV isolates of passionfruit from Thailand. These observations suggest the following scenario: TelMV was jumped from one or several unknown host plant species to passionfruit in Thailand. After that, it was dispersed to East Asia, possibly via the infected propagation materials of passionfruit. The host jump may have occurred multiple times, resulting in the establishment of several distinct clades of TelMV in passionfruit plants of Thailand. The dispersal, however, may have occurred only once, so that a single clade of TelMV is found in passionfruit plants of China and Vietnam. The TelMV clade infecting telosma in Vietnam and Emperor's Candlesticks in China is not found in passionfruit of these two countries. This suggests that the host jump of TelMV is not as easy as it is envisioned. Thus, the host plant of TelMV in Thailand may have a closer relationship with passionfruit than with telosma and Emperor's Candlesticks. Although many more studies are required to confirm these ideas, our study for the first time offers a framework to dissect the mechanisms underlying the emergence of a potyvirus in passionfruit.

Geography-associated evolution seems to be common to plant viruses including potyviruses (Gao et al. 2016, 2017). Therefore, the geographical differentiation of Clade 1 TelMV detected in this study is not unexpected. The pattern of the differentiation, however, is interesting and relevant to TelMV management. For example, the TelMV population in Hainan Province is significantly different from those in other provinces of China. This correlates with the fact that the extension of passionfruit cultivation in Hainan is much later than that in other provinces of China. To protect passionfruit from viral diseases that had already been rampant in other provinces, Hainan provincial government implemented strict quarantine measures, which might have significantly lowered the frequency of TelMV immigration. Similarly, the TelMV population in Taiwan is different from that in China's mainland. This corelates with the fact that Taiwan has made much more efforts than China's mainland in the development and use of virus-free propagation materials of passionfruit.

At last, we found that purifying selection is acting on the CP of Clade 1 TelMV. This is also not unexpected because most amino acid changes in $\mathrm{CP}$ may be detrimental to TelMV. What is interesting is that we also detected several positively selected amino acid substitutions. The effect of these amino acid substitutions on the infectivity, transmission and fitness of TelMV deserves further studies.

\section{Conclusions}

Several distinct TelMV clades had arisen from passionfruit plants of Thailand, but only one of which was dispersed in East and Southeast Asia. In expanding its distribution, this clade of TelMV is undergoing geography-associated evolution. In China, TelMV has become one important, if not the most important, potyvirus infecting passionfruit plants.

\section{Methods}

\section{Sample collection}

Samples were collected between May 2019 and July 2020 from 25 counties located in 7 provinces of China (Fig. 1a). As passionfruit hectarage varies greatly in each province and county, the sampled counties for each province vary from 1 to 9 and the sampled orchards for each county vary from 6 to 40. The distance between the sampled 
orchards within each county ranges from 5 to more than $10 \mathrm{~km}$, depending on passionfruit availability. Five points were randomly chosen in each orchard and 2 passionfruit plants were sampled from each point regardless of whether they showed virus-like symptoms. The samples were taken to the laboratory and stored at $-80{ }^{\circ} \mathrm{C}$ until use. The number of samples obtained are 204, 61, 113, 65, 35, 12 and 18 for Fujian (FJ), Guangdong (GD), Guangxi (GX), Hainan (HN), Jiangsu (JS), Sichuan (SC) and Yunnan (YN) provinces, respectively (Fig. 1a).

\section{TelMV detection and $\mathrm{CP}$ sequencing}

Total RNA was extracted from each sample using an RNAprep pure Plant Kit (TIANGEN Biotech Co., Beijing) and reverse transcribed using SuperScript III reverse transcriptase (Invitrogen, Carlsbad, CA, USA) with an oligo-dT primer. The CDNA was amplified with a primer pair (forward primer: $5^{\prime}$-AGCTCTACACTGACA AGGATGCC-3', reverse primer: 5'-GCAATACTCATG AACAAGGTGGT-3') flanking the CP of TelMV. The product of each RT-PCR was resolved by electrophoresis in a $1 \%$ agarose gel and visualized after ethidium bromide staining. In each reaction, healthy passionfruit seedlings grown in a greenhouse of our lab was used as a negative control. A passionfruit sample in which the presence of TelMV had been confirmed independently was used as a positive control. To determine the $\mathrm{CP}$ gene sequence of TelMV, the RT-PCR product was recovered from the gel and sequenced bidirectionally.

\section{Sequence data set and recombination analysis}

The CP gene sequences of 96 TelMV isolates were obtained in this study. These sequences were combined with relevant data available from GenBank to form a data set consisting of 140 sequences, which were grouped into 10 geographical populations: Anhui (AH, $n=8)$, Fujian (FJ, $n=30$ ), Guangdong (GD, $n=12$ ), Guangxi (GX, $n=21$ ), Hainan (HN, $n=16$ ), Jiangsu (JS, $n=15$ ), Yunnan (YN, $n=6$ ), Taiwan (TW, $n=11$ ), Thailand (TL, $n=19$ ) and Viet Nam (VN, $n=2)$ (Additional file 3: Table S2). Codon-based sequence alignment was performed using MUSCLE program (Edgar 2004) implemented in MEGA $X$ (Kumar et al. 2018) and used for population genetics analysis. The sequence alignment had a length of 816 nucleotides after excluding the stop codons. The potential recombination events were examined using the Phi test (Pairwise homoplasy index) implemented in SplitsTree (Huson 1998) and also identified using the Recombination Detection Program (RDP) 4.101 (Martin et al. 2015). We found no evidence of recombination signal in the data set using either of the two methods, so we used the complete data set for all of our subsequent analyses.

\section{Phylogeny reconstruction}

A maximum-likelihood-based phylogenetic analysis was performed using IQ-tree 2.12 (Minh et al. 2020) under the $\mathrm{TN}+\mathrm{F}+\Gamma_{4}+\mathrm{I}$ substitution model, which was chosen using ModelFinder (Kalyaanamoorthy et al. 2017) with Bayesian information criterion as implemented in IQtree. Topological support for the inferred tree was estimated by bootstrapping with 10,000 ultrafast bootstrap replicates (Hoang et al. 2018).

\section{Genetic diversity and population differentiation}

To estimate genetic diversity parameters, haplotype and nucleotide diversities were calculated using DnaSP 5.10 (Librado and Rozas 2009). To measure the amount of genetic divergence among the sampled populations, pairwise $F_{\mathrm{ST}}$ was examined using Arlequin 3.5 (Excoffier and Lischer 2010). The statistical significance of the $F_{\mathrm{ST}}$ values was tested based on 10,100 permutations (default). The criterion for genetic differentiation was defined as follows: low for $F_{\mathrm{ST}}<0.05$, moderate for $0.05<F_{\mathrm{ST}}<0.15$, high for $0.15<F_{\mathrm{ST}}<0.25$, and very high for $F_{\mathrm{ST}}>0.25$ (Balloux and Lugon-Moulin 2002). In addition, the $F_{\mathrm{ST}}$ value was also used to measure levels of gene flow with the following criterion: frequent gene flow for $F_{\mathrm{ST}}<0.33$, infrequent gene flow for $F_{\mathrm{ST}}>0.33$.

\section{Phylogeny-trait association analysis}

To estimate the effect of the geographic origin on TelMV populations, a phylogenetic-trait association analysis was performed to calculate association index $(A I)$, parsimony score $(P S)$ and maximum monophyletic clade size $(M C)$ using BaTS 2.0 (Parker et al. 2008). This analysis compared the posterior sample of trees, from the Bayesian analysis implemented in BEAST 1.10.4 (Suchard et al. 2018) to a null distribution of 1000 location-randomized trees. Our interpretation of the results followed the guidelines of Parker et al. (2008). Briefly, low AI index and $P S$ and high $M C$ scores suggest a strong phylogeny-geography association and low spatial admixture. For the Bayesian analysis, MCMC runs were performed under the GTR $+\mathrm{F}+\Gamma_{4}+\mathrm{I}$ substitution model, which was determined by ModelFinder. To choose the fit of the strict clock and the uncorrelated lognormal relaxed clock, marginal likelihoods were computed using stepping-stone sampling (Baele et al. 2012). The uncorrelated lognormal relaxed clock had a higher log marginal likelihood $(-5861.32)$ than the strict clock $(-5869.45)$, indicating that a relaxed clock model provided the best fit to our sequence data and was used to the BSP analysis. Two independent MCMC runs were conducted, with samples drawn every 5,000 steps over 500 million steps. Posterior 
distributions of all parameters were checked by the effective sample sizes $(E S S>200)$ using Tracer 1.7 (Rambaut et al. 2018).

\section{Test for natural selection}

To evaluate the role of natural selection in shaping the adaptive genetic diversity, the inference of positive selection was performed using the site models of CODEML algorithm (Yang 2007) implemented in EasyCodeML (Gao et al. 2019). For this analysis, the site models assume variation in the ratio of nonsynonymous $(d \mathrm{~N})$ to synonymous $(d \mathrm{~S})$ substitution rates $(\omega=d \mathrm{~N} / d \mathrm{~S})$ among sites in the alignment but not across clades of the phylogeny (Yang and Nielsen 2002). The codon-based substitution models M0 (one-ratio), M1a (nearly neutral), M2a (positive selection), M3 (discrete), M7 (beta), M8 (beta and $\omega>1$ ) and M8a (beta and $\omega=1$ ) were investigated. To select the best-fit models to the sequence data, likelihood-ratio tests (LRTs) were conducted by comparing twice the difference in $\log$-likelihood values $(2 \Delta \mathrm{LnL})$ to a $x^{2}$-distribution with degrees of freedom equal to the difference in the number of parameters between models to be compared (M1a vs. M2a, M7 vs. M8, and M8a vs. M8). The Bayes empirical Bayes (BEB) method (Yang et al. 2005) was used to identify the positively selected sites when a LRT yields a significant result for these nested models.

\section{Abbreviations}

Al: Association index; BEB: Bayes empirical Bayes; CABMV: Cowpea aphidborne mosaic virus; CP: Coat protein; LRT: Likelihood-ratio test; MC: Maximum monophyletic clade size; PS: Parsimony score; PWD: Passionfruit woodiness disease; PWV: Passionfruit woodiness virus; TelMV: Telosma mosaic virus.

\section{Supplementary Information}

The online version contains supplementary material available at https://doi. org/10.1186/s42483-021-00101-1.

Additional file 1. Figure S1. Maximum-likelihood phylogenetic tree based on the nucleotide sequences of the coat protein gene of Clade 1 TeIMV. Ultrafast bootstrap support $>95 \%$ values are given at each node. TelMV isolates from different regions are indicated by a unique color. The bar represents the number of substitutions per site.

Additional file 2. Table S1. Selection analysis for the CP gene sequences of TelMV within Clade 3.

Additional file 3. Table S2. Telosma mosaic virus isolates used in this study.

\section{Acknowledgements}

Not applicable.

\section{Authors' contributions}

ZW conceived the study. CY, QL, HL, LC, YL, YZ and XH performed the experiments. ZD and FG analyzed the data and interpreted the results. ZD, FG and $Z W$ took the lead in writing the manuscript. All authors read and approved the final manuscript.

\section{Funding}

This work was supported by the Natural Science Foundation of China (Grant No. 31772103), the Natural Science Foundation of Fujian Province of China (Grant No. 2019J01653) and a grant from Fujian Agriculture and Forestry University (Grant No. CXZX2016130)

\section{Availability of data and materials}

The datasets generated for this study are available in the GenBank database, with accession numbers MZ509559-MZ509659.

\section{Declarations}

Ethical approval and consent to participate

Not applicable.

\section{Consent for publication}

Not applicable.

\section{Competing interests}

The authors declare that they have no competing interests.

\section{Author details}

${ }^{1}$ Institute of Plant Virology, Fujian Agriculture and Forestry University, Fuzhou 350002, China. ${ }^{2}$ State Key Laboratory of Ecological Pest Control for Fujian and Taiwan Crops, Fujian Agriculture and Forestry University, Fuzhou 350002, China

Received: 11 August 2021 Accepted: 24 September 202

Published online: 06 October 2021

\section{References}

Alfenas PF, Braz ASK, Torres LB, Santana EN, do Nascimento AVS, de Carvalho $M G$, et al. Transgenic passionfruit expressing RNA derived from cowpea aphid-borne mosaic virus is resistant to passionfruit woodiness disease. Fitopatol Bras. 2005;30:33-8. https://doi.org/10.1590/S0100-41582 005000100006

Baele G, Lemey P, Bedford T, Rambaut A, Suchard MA, Alekseyenko AV. Improving the accuracy of demographic and molecular clock model comparison while accommodating phylogenetic uncertainty. Mol Biol Evol. 2012;29(9):2157-67. https://doi.org/10.1093/molbev/mss084.

Balloux F, Lugon-Moulin N. The estimation of population differentiation with microsatellite markers. Mol Ecol. 2002;11(2):155-65. https://doi.org/10. 1046/j.0962-1083.2001.01436.x

Cerqueira-Silva CBM, Conceição LDHCS, Souza AP, Corrêa RX. A history of passion fruit woodiness disease with emphasis on the current situation in Brazil and prospects for Brazilian passion fruit cultivation. Eur J Plant Pathol. 2014;139:261-70. https://doi.org/10.1007/s10658-014-0391-z.

Chang CA. Characterization and comparison of passionfruit mottle virus, a newly recognized potyvirus, with passionfruit woodiness virus. Phytopathology. 1992;82:1358-63. https://doi.org/10.1094/Phyto-82-1358.

Chen S, Yu N, Yang S, Zhong B, Lan H. Identification of telosma mosaic virus infection in Passiflora edulis and its impact on phytochemical contents. Virol J. 2018:15:168. https://doi.org/10.1186/s12985-018-1084-6.

Chiemsombat P, Prammanee S, Pipattanawong N. Occurrence of telosma mosaic virus causing passion fruit severe mosaic disease in Thailand and immunostrip test for rapid virus detection. Crop Prot. 2014;63:417. https://doi.org/10.1016/j.cropro.2014.04.023.

Chong Y-H, Cheng Y-H, Cheng H-W, Huang Y-C, Yeh S-D. The virus causing passionfruit woodiness disease in Taiwan is reclassified as East Asian passiflora virus. J Gen Plant Pathol. 2018;84:208-20. https://doi.org/10. 1007/s10327-018-0777-4

Do DH, Chong YH, Ha VC, Cheng HW, Chen YK, Bui TNL, et al. Characterization and detection of passiflora mottle virus and other two potyviruses causing passionfruit woodiness disease in Vietnam. Phytopathology. 2021. https://doi.org/10.1094/PHYTO-10-20-0481-R.

Edgar RC. MUSCLE: multiple sequence alignment with high accuracy and high throughput. Nucleic Acids Res. 2004;32(5):1792-7. https://doi.org/10. 1093/nar/gkh340. 
Excoffier L, Lischer HEL. Arlequin suite ver 3.5: a new series of programs to perform population genetics analyses under Linux and Windows. Mol Ecol Res. 2010;10:564-7. https://doi.org/10.1111/j.1755-0998.2010.02847.x.

Gao F, Chen C, Arab DA, Du Z, He Y, Ho SYW. EasyCodeML: a visual tool for analysis of selection using CodeML. Ecol Evol. 2019;9(7):3891-8. https:// doi.org/10.1002/ece3.5015.

Gao F, Jin J, Zou W, Liao F, Shen J. Geographically driven adaptation of chilli veinal mottle virus revealed by genetic diversity analysis of the coat protein gene. Arch Virol. 2016;161:1329-33. https://doi.org/10.1007/ s00705-016-2761-7.

Gao F, Zou W, Xie L, Zhan J. Adaptive evolution and demographic history contribute to the divergent population genetic structure of potato virus Y between China and Japan. Evol Appl. 2017;10(4):379-90. https://doi. org/10.1111/eva.12459.

Ha C, Coombs S, Revill PA, Harding RM, Vu M, Dale JL. Design and application of two novel degenerate primer pairs for the detection and complete genomic characterization of potyviruses. Arch Virolo. 2008;153:25-36. https://doi.org/10.1007/s00705-007-1053-7.

$\mathrm{Ha}$ CV. Detection and identification of potyviruses and geminiviruses in Vietnam. PhD thesis. Queensland University of Technology. 2007.

Hoang DT, Chernomor O, von Haeseler A, Minh BQ, Vinh LS. UFBoot2: Improving the ultrafast bootstrap approximation. Mol Biol Evol. 2018;35(2):51822. https://doi.org/10.1093/molbev/msx281.

Huson DH. SplitsTree: analyzing and visualizing evolutionary data. Bioinformatics. 1998;14(1):68-73. https://doi.org/10.1093/bioinformatics/14.1.68.

Iwai H, Yamashita Y, Nishi N, Nakamura M. The potyvirus associated with the dappled fruit of Passiflora edulis in Kagoshima prefecture, Japan is the third strain of the proposed new species East Asian passiflora virus (EAPV) phylogenetically distinguished from strains of passion fruit woodiness virus. Arch Virol. 2006;151:811-8. https://doi.org/10.1007/ s00705-005-0659-x.

Kalyaanamoorthy S, Minh BQ, Wong TKF, von Haeseler A, Jermiin LS. ModelFinder: fast model selection for accurate phylogenetic estimates. Nat Methods. 2017;14(6):587-9. https://doi.org/10.1038/nmeth.4285.

Kumar S, Stecher G, Li M, Knyaz C, Tamura K. MEGA X: molecular evolutionary genetics analysis across computing platforms. Mol Biol Evol. 2018;35(6):1547-9. https://doi.org/10.1093/molbev/msy096.

Librado P, Rozas J. DnaSP v5: a software for comprehensive a.nalysis of DNA polymorphism data. Bioinformatics. 2009;25(11):1451-2. https://doi.org/ 10.1093/bioinformatics/btp187.

Lim TK. Passiflora edulis. In: Edible medicinal and non-medicinal plants. Dordrecht: Springer; 2012. 147-65. https://doi.org/10.1007/978-94-0074053-2_21.

Manicom B, Ruggiero C, Ploetz R, Goes AD. Diseases of passion fruit. Dis Trop Fruit Crops. 2003;413-41.

Martin DP, Murrell B, Golden M, Khoosal A, Muhire B. RDP4: detection and analysis of recombination patterns in virus genomes. Virus Evol. 2015;1(1):vev003. https://doi.org/10.1093/ve/vev003.

Mbeyagala EK, Maina S, Macharia MW, Mukasa SB, Holton T. Illumina sequencing reveals the first near-complete genome sequence of Ugandan passiflora virus. Microbiol Resour Announce. 2019;8. https://doi.org/10. 1128/MRA.00358-19.
Minh BQ, Schmidt HA, Chernomor O, Schrempf D, Woodhams MD, von Haeseler A, Lanfear R. IQ-TREE 2: New models and efficient methods for phylogenetic inference in the genomic era. Mol Biol Evol. 2020;37(5):1530-4. https://doi.org/10.1093/molbev/msaa015.

Ochwo-Ssemakula M, Sengooba T, Hakiza JJ, Adipala E, Edema R, Redinbaugh $M G$, et al. Characterization and distribution of a Potyvirus associated with passion fruit woodiness disease in Uganda. Plant Dis. 2011;96(5):659-65. https://doi.org/10.1094/PDIS-03-11-0263.

Parker J, Rambaut A, Pybus OG. Correlating viral phenotypes with phylogeny: accounting for phylogenetic uncertainty. Infec Genet Evol. 2008;8:23946. https://doi.org/10.1016/j.meegid.2007.08.001.

Peasley D. Passionfruit industry benefits through scionwood scheme. Agricultural Gazette of New South Wales. 1981.

Rambaut A, Drummond AJ, Xie D, Baele G, Suchard MA. Posterior summarisation in Bayesian phylogenetics using Tracer 1.7. Syst Biol. 2018;67(5):9014. https://doi.org/10.1093/sysbio/syy032.

Rubio L, Galipienso L, Ferriol I. Detection of plant viruses and disease management: relevance of genetic diversity and evolution. Front Plant Sci. 2020;11:1092. https://doi.org/10.3389/fpls.2020.01092.

Suchard MA, Lemey P, Baele G, Ayres DL, Drummond AJ, Rambaut A. Bayesian phylogenetic and phylodynamic data integration using BEAST 1.10. Virus Evol. 2018;4(1):vey016. https://doi.org/10.1093/ve/vey016.

Taylor RH, Greber RS. Passionfruit woodiness virus. CMI/AAB. Descriptions of Plant Viruses. 122. 1973

Trevisan F. Transformação genética de maracujazeiro (Passiflora edulis f. flavicarpa) para resistência ao vírus do endurecimento dos frutos. Biblioteca Digital De Teses E Dissertaes Da Universidade De So Paulo. 2005. https:// teses.usp.br/teses/disponiveis/11/11144/tde-29092005-134710/publico/ FlavioTrevisan.pdf.

Xie L, Zhang X, Zheng S, Zhang L, Li T. Molecular identification and specific detection of telosma mosaic virus infecting passion fruit. Sci Agric Sin. 2017;50(24):4725-34. https://doi.org/10.3864/j.issn.0578-1752.2017.24. 006 (in Chinese)

Yang Z. PAML 4: phylogenetic analysis by maximum likelihood. Mol Biol Evol. 2007;24(8):1586-91. https://doi.org/10.1093/molbev/msm088.

Yang Z, Nielsen R. Codon-substitution models for detecting molecular adaptation at individual sites along specific lineages. Mol Biol Evol. 2002;19(6):908-17. https://doi.org/10.1093/oxfordjournals.molbev.a0041 48.

Yang Z, Wong WSW, Nielsen R. Bayes empirical Bayes inference of amino acid sites under positive selection. Mol Biol Evol. 2005;22(4):1107-18. https:// doi.org/10.1093/molbev/msi097.

Yao LZ, Li XQ, Wang JG, Chen SY, Wang XJ. First report of telosma mosaic virus infecting Emperor's Candlesticks (Senna alata) in China. Plant Dis. 2019;103(3):594. https://doi.org/10.1094/PDIS-04-18-0706-PDN.

\section{Publisher's Note}

Springer Nature remains neutral with regard to jurisdictional claims in published maps and institutional affiliations.

Ready to submit your research? Choose BMC and benefit from

- fast, convenient online submission

- thorough peer review by experienced researchers in your field

- rapid publication on acceptance

- support for research data, including large and complex data types

- gold Open Access which fosters wider collaboration and increased citations

- maximum visibility for your research: over $100 \mathrm{M}$ website views per year

At BMC, research is always in progress.

Learn more biomedcentral.com/submissions 